\title{
Game Analysis of Government and Enterprises in the Reverse Logistics of Waste Household Appliances
}

\author{
Jiani Lou ${ }^{1, a}$ and Tianjun $\mathrm{Hu}^{1, \mathrm{~b}}$ \\ ${ }^{1}$ Beijing Jiaotong University, Beijing, China

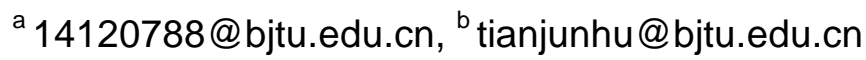

Keywords: Reverse logistics; Waste household appliances; Static game; Dynamic game.

Abstract. This paper uses game theory to analyze the behavior of government and enterprises in the Reverse Logistics (RL) of Waste Household Appliances (WHA). A static game model and a dynamic game model are established to study respectively the periods of establishing and operating the Reverse Logistics System (RLS). We find that (1)enterprises will establish the RLS when government can levy heavy fine on those not establishing the RLS and when enterprises make profits from establishing; (2)enterprises will operate the RLS actively when government subsidize them much. Then we discuss accordingly the strategies government should adopt in the RL of WHA. This paper contributes to the theoretical analysis and policy practices of reverse logistics of waste household appliances from the perspective of game theory.

\section{Introduction}

China is a "Great Power" in the production and consuming household appliances. The huge popularity and high updating rate generate lots of Waste Household Appliances (WHA). It is anticipated that 160 million WHA will be eliminated in our country in 2015. Treated improperly, they may cause serious environmental pollution and waste of resources. The key to solving the problem is to build a comprehensive Reverse Logistics System (RLS).

Our exploration of this problem has a long history, but is still at the initial exploration stage. Lack of supervision by the government, low environmental awareness by the public, and the poor recycling technology, high initial investment costs and lack of effective self-regulatory mechanism by enterprises, all lead to difficulties in constructing and implementing reverse logistics of WHA. Reverse Logistics (RL) of WHA is a special investment of social welfare to meet the greatest welfare, so it is difficult to solve the problem only by means of market mechanisms without reasonable return.

Under this circumstance, appropriate macro-control by government is essential to establish a relatively through restraint and incentive mechanism, in order to encourage enterprises to build and implement RL. After enterprise implementing RL, environmental benefits and social welfare will be greatly enhanced. On this basis, the government and enterprises find a balance point in the game, and jointly promote the development of reverse logistics.

\section{Review of Literature}

National Standard of Logistics Term (GB/TI 8354-2006) has defined reverse logistics as follows: The Reverse Logistics (RL) is the logistics activities caused by the movement of items upstream through the supply chain. The standard divides RL into two categories: (1) Recycling Logistics, namely the logistics activities from the demand side to the supply side, including return of goods, reworking of items, turnover of packaging containers, etc; (2) Waste Logistics, namely the logistics activities of collecting, sorting, processing, packaging, handling and storing items out of using value in the economic activities according to the actual needs, and distributing them to special disposal sites. This paper mainly analyzes and discusses for the latter kind, Waste Logistics.

Among literature abroad, Markus Klausner and Hendricksonl(2000) examine ways to reduce costs when manufacturers implement waste product recall in the ERP system, and take the product recycling of Power Tool in Germany as an example to analyze quantitatively regarding processing costs and 
freight recovery; Hsing shi-PI(2001) analyzes specifically the game of government regulation and enterprises RL behavior, Taiwan as an example; Tung LaiHu et al (2002) establish a discrete linear model to analyze the cost minimization of the RL of hazardous waste, and analyze the game problem with government from inside the enterprises, in order to develop the optimal RL decision for enterprises; Hammond et al (2007) establish a Cournot pricing model concerning a CLSC consisting of multiple manufacturers and consumers with full information, and prove that the equilibrium exists in the CLSC for all members to get the most benefit, when all the supply chain members agree on transaction volume and price.

Among domestic literature, Guilin Dai et al (2008) analyze the problem of WHA recycling confronting cities in China in the process of developing sustainably, propose countermeasures of the problem from levels of enterprises and government, and provide reasonable proposals to resolve the environmental and resource problems brought by WHA and city development; Peiwu Zhu(2010) studies the measures taken by developed countries in the process of WHA, and then discusses the existing problems in the WHA recycle from the aspect of the licensing system and other industrial systems; Chuanxu Wang (2003) attempts to put forward a dynamic game model of reverse logistics using game theory and related mathematical tools, and deduce corrected dynamic game analysis equation model; Xiaomei Jia and Jingfei Ran(2005) analyze the game model of recycling logistics and waste logistics with and without institutional arrangements, and conclude the game model for general RL with institutional arrangements; Jinyong Li(2007) introduces liability losses mechanism into the balanced strategy game of government and enterprises, compare the new balance with the original balance, and conclude that the introduction of liability losses mechanism encourages government and enterprises to consciously carry out RL; Wensheng He and Zujun $\mathrm{Ma}(2008)$ analyze the equalization benefits of appliance manufacturers to recycle discarded appliances, establish a dynamic game model of appliance manufacturers to implement recycling stream based on multidimensional game theory, analyze the multidimensional game issue of two enterprises concerning product brand benefits, recycling logistics investment and the market price when implementing WHA recycling, and get the corresponding equilibrium and optimal management strategy in equilibrium benefits; Jianbin Li and Yang Liu(2009) discuss the effects of subsidies and fines in a single game through the analysis of the interaction between governments and enterprises, and elaborate the measures government should take using the theory of repeated games; Xiaofeng Liu and Shuang Chen(2009) analyze how can the government promote productive enterprises to carry out a comprehensive RL from the perspective of economic incentives using a multi-tasking principal-agent model, and conclude that government should take reasonable measures to incentivize enterprises according to the substitution of the work effort cost in different aspects in the RL.

Our current research on RL of WHA is more concentrated in universities and research institutions, whereas not widely carried out in the enterprise and lacking practical application research, which leads to the inconspicuousness of the guiding role of some of the current findings to the policy. Therefore we should combine with the actual situation of China's current research when learning from the advanced experience of foreign countries to gradually expand the RL, in order to make theoretical guidance for the formulation of policies concerning RL of WHA.

\section{The Static Game of Establishing the RLS}

Enterprises need to invest a lot when implementing the RL, and can hardly make profit due to scale and technology, which prevent enterprises from establishing the Reverse Logistics System (RLS) initiatively. So it is necessary for government to promote enterprises to build RLS through the development of incentives. Government and enterprises can jointly implement and promote the RL under an acceptable equilibrium condition by gaming.

Construction of the Static Game Model. When establishing the RLS, potential choices for government are "to monitor" and "not to monitor", while potential choices for enterprises are "to establish" and "not to establish". Government and enterprises do not know each other's choice of 
strategy either during the game, so it can be seen as a static game. And they know the potential revenue of each other, namely the game is with full information. Therefore, the game of establishing the RLS is a Static Game with Full Information.

If government monitors and enterprises do not establish the RLS, enterprises should be held responsible for treating the environmental damage. Else if government does not monitor and enterprises do not establish the RLS, government pays for that treatment cost.

Parameters of the model are set as follows:

NR - Normal Revenue, before establishment of the Reverse Logistics System (RLS);

$\mathrm{CR}$ - Construction Revenue, gains for enterprises in the reverse logistics activities;

ER-Environmental Revenue, gains for enterprises after construction of the RLS;

$\mathrm{CC}$ - Construction Cost, cost for enterprises to establish the RLS;

MC-Monitoring Cost, for government;

TC-Treatment Cost, if the RLS were not established, for either enterprises or government;

$\mathrm{F}$-Fine, by government to enterprises if not establishing the RLS.

The Payoff Matrix of Enterprises and Government is as follows:

Table 1 Payoff Matrix of Enterprises and Government

\begin{tabular}{ccc}
\hline Enterprises & To Monitor & Not to Monitor \\
\hline To Establish & NR+CR-CC, ER-MC & NR+CR-CC, ER \\
Not to Establish & NR-TC-F, F-MC & NR, -TC \\
\hline
\end{tabular}

Pure-strategy Nash Equilibrium of the Static Game. When establishing the RLS, potential choices for government are "to monitor" and "not to monitor", while potential choices for enterprises are "to establish" and "not to establish". Government and enterprises do not know each other's choice of strategy either during the game, so it can be seen as a static game. And they know the potential revenue of each other, namely the game is with full information. Therefore, the game of establishing the RLS is a Static Game with Full Information.

Then we solve the game model according to the Payoff Matrix of Enterprises and Government.

When the parameters meet different conditions, enterprises and the government will make a different decision, summarized in the following table:

Table 2 Conditions and Decisions

\begin{tabular}{cll}
\hline Entity & \multicolumn{1}{c}{ Condition } & \multicolumn{1}{c}{ Decision } \\
\hline \multirow{3}{*}{ Enterprises } & $-\mathrm{TC}-\mathrm{F}<0<C R-C C$ & To establish \\
\cline { 2 - 3 } & $-\mathrm{TC}-\mathrm{F}<C R-C C<0$ & $\begin{array}{l}\text { To establish if monitored; } \\
\text { not to otherwise }\end{array}$ \\
\cline { 2 - 3 } Government & $\mathrm{CR}-\mathrm{C} C<-\mathrm{TC}-\mathrm{F}<0$ & Not to establish \\
\cline { 2 - 3 } & $\mathrm{F}-\mathrm{MC}>-\mathrm{TC}$ & $\begin{array}{l}\text { To monitor if } \mathrm{RLC} \text { not established; } \\
\text { not to otherwise }\end{array}$ \\
\cline { 2 - 3 } & $\mathrm{F}-\mathrm{MC}<-\mathrm{TC}$ & Not to monitor \\
\hline
\end{tabular}

Conditions of parameters confronting enterprises and government combined, we get Nash Equilibrium under different conditions, summarized in the following table: 
Table 3 Pure-strategy Nash Equilibrium

\begin{tabular}{c|c|c}
\hline Government & $\mathrm{F}-\mathrm{MC}>-\mathrm{TC}$ & $\mathrm{F}-\mathrm{MC}<-\mathrm{TC}$ \\
\hline$-\mathrm{TC}-\mathrm{F}<0<\mathbf{C R}-\mathbf{C C}$ & (Construct, Not Monitor) & (Construct, Not Monitor) \\
\hline$-\mathrm{TC}-\mathrm{F}<\mathbf{C R}-\mathbf{C C}<0$ & & (Not Construct, Not Monitor) \\
\hline $\mathbf{C R}-\mathbf{C C}<-\mathrm{TC}-\mathrm{F}<0$ & (Not Construct, Monitor) & (Not Construct, Not Monitor) \\
\hline
\end{tabular}

To sum up, we get 3 kinds of pure-strategy Nash equilibrium: (Construct, Not Monitor), (Not Construct, Not Monitor), and (Not Construct, Monitor).

Mixed-strategy Nash Equilibrium of the Static Game. According to the analysis above, there exists no Pure-strategy Nash Equilibrium when $-\mathrm{TC}-\mathrm{F}<\mathrm{CR}-\mathrm{CC}<0$ and F $-\mathrm{MC}>-\mathrm{TC}$. Suppose that Enterprises chose Mixed Strategy $A=(\alpha, 1-\alpha)$, i.e. to establish the RLS in the probability of $\alpha$, and of $(1-\alpha)$ otherwise. Government chose Mixed Strategy $B=(\beta, 1-\beta)$, i.e. to monitor in the probability of $\beta$, and of $(1-\beta)$ otherwise.

Therefore the Expected Revenue Function of enterprises is:

$$
\begin{aligned}
\mathrm{RE} & =(\mathrm{NR}+\mathrm{CR}-\mathrm{CC}) \alpha \beta+(\mathrm{NR}+\mathrm{CR}-\mathrm{CC}) \alpha(1-\beta)+(\mathrm{NR}-\mathrm{TC}-\mathrm{F})(1-\alpha) \beta+\mathrm{NR}(1-\alpha)(1-\beta) \\
& =\alpha \beta(\mathrm{TC}+\mathrm{F})+\alpha(\mathrm{CR}-\mathrm{CC})-\beta(\mathrm{TC}+\mathrm{F})+\mathrm{NR}
\end{aligned}
$$

Expected Revenue Function of government is:

$$
\begin{aligned}
\mathrm{RG} & =(\mathrm{ER}-\mathrm{MC}) \alpha \beta+\mathrm{ER} \alpha(1-\beta)+(\mathrm{F}-\mathrm{MC})(1-\alpha) \beta+(-\mathrm{TC})(1-\alpha)(1-\beta) \\
& =-\alpha \beta(\mathrm{TC}+\mathrm{F})+\alpha(\mathrm{ER}+\mathrm{TC})+\beta(\mathrm{TC}+\mathrm{F}-\mathrm{MC})-\mathrm{TC}
\end{aligned}
$$

To figure out the Nash Equilibrium, we are to resolve the optimization problem:

$$
\left\{\begin{array}{l}
\max _{\alpha \in A} R_{E}(\alpha, \beta) \\
=\max _{0<\alpha<1}[\alpha \beta(T C+F)+\alpha(C R-C C)-\beta(T C+F)+N R] \\
\max _{\beta \in b} R_{G}(\alpha, \beta) \\
=\max _{0<\beta<1}[-\alpha \beta(T C+F)+\alpha(E R+T C)+\beta(T C+F-M C)-T C]
\end{array}\right.
$$

The first-order differential conditions for optimization are:

$$
\left\{\begin{array} { l } 
{ \frac { \partial R _ { E } } { \partial \alpha } = 0 } \\
{ \frac { \partial R _ { G } } { \partial \beta } = 0 }
\end{array} , \text { namely } \left\{\begin{array}{l}
\beta(T C+F)+(C R-C C)=0 \\
-\alpha(T C+F)+(T C+F-M C)=0
\end{array} .\right.\right.
$$

The solution is: $\left\{\begin{array}{l}\alpha^{*}=\frac{T C+F-M C}{T C+F} \\ \beta^{*}=\frac{C C-C R}{T C+F}\end{array}\right.$

So the equilibrium of the Mixed-strategy Nash Equilibrium is: 


$$
\left\{\begin{array}{l}
A^{*}=\left(1-\frac{M C}{T C+F}, \frac{M C}{T C+F}\right) \\
B^{*}=\left(\frac{C C-C R}{T C+F}, 1-\frac{C C-C R}{T C+F}\right)
\end{array}\right.
$$

That is, enterprises establish the RLS in the probability of $\left(1-\frac{M C}{T C+F}\right)$, and government monitors enterprises in the probability of $\left(\frac{C C-C R}{T C+F}\right)$.

\section{The Dynamic Game of Operating the Reverse Logistics System}

Actions and their sequences of government and enterprises in the RL of WHA are common information for each side, so the stage game is with full information.

Recycling must be considered during production if enterprises are to establish the RLS. Construction of the RLS needs a lot of investment, and enterprises have to pay when recycling and remanufacturing, whereas earnings from recycling products may not justify the cost in the early period. In this case, enterprises will choose not to recycle. In order to encourage enterprises to carry out the RL business, government should offer some support, including tax incentives and subsidies.

Then we construct the stage game model of operating the RLS.

(1) As discussed above, if government does not subsidize enterprises, the latter will not implement RL. And if government subsidizes, enterprises can choose to recycle positively or negatively.

(2) The government set a recycling amount for enterprises. If the real amount is more than the set amount, we call it "High Recycling Amount", and "Low Recycling Amount" if less. When positively recycling, enterprises work harder so the cost is higher, for example, setting up more recycling stations, carrying out trade-in programs and organizing staff training. We assume negative recycling without these costs.

(3) We also assume that when positively recycling, enterprises can realize high amount for sure. And when negatively recycling, enterprises get high and low amount in the probabilities of $p$ and (1-p) respectively. So the appearance of low amount means that enterprises surely recycle negatively.

Parameters of the model are set as follows:

OC-Opportunity Cost, if enterprises conducted the RLS system;

Q-Quantity, of disused household appliances;

$\mathrm{s}$-Subsidy, from government to enterprises per appliance;

$\mathrm{qH}-$ High Quantity, of recycled appliances;

qL-Low Quantity, of recycled appliances;

DR - Disposing Revenue, per appliance recycled;

$\mathrm{DC}$-Disposing Cost, per appliance recycled;

RC-Recycling Cost, per appliance disused;

$\mathrm{HC}$-Hard-working Cost, per appliance recycled;

$\mathrm{r}$ - Ratio of reutilization, of appliance recycled;

UC-Unused Cost, per appliance recycled;

TC-Treatment Cost, for government, per appliance disused;

ER-Environmental Revenue, per appliance recycled.

The situations of the stage game can be described as follows: 
Table 4 The Stage Game

\begin{tabular}{|c|c|c|c|}
\hline Gov. & Enter. & Recycled & Revenues \\
\hline Not subsidize & $\begin{array}{l}\text { Not } \\
\text { recycle }\end{array}$ & None & $(\mathrm{OC},-\mathrm{TC} \cdot \mathrm{Q})$ \\
\hline \multirow{3}{*}{ Subsidize } & Positive & High & $\begin{array}{l}{\left[(\mathrm{s}+\mathrm{DR}-\mathrm{DC}-\mathrm{RC}) \mathrm{r} \cdot \mathrm{q}_{\mathrm{H}}+(\mathrm{s}-\mathrm{RC}-\mathrm{UC})(1-\mathrm{r}) \mathrm{q}_{\mathrm{H}}-\mathrm{HC} \cdot \mathrm{q}_{\mathrm{H}},\right.} \\
\left.(\mathrm{ER}-\mathrm{s}) \mathrm{q}_{\mathrm{H}}-\mathrm{TC}\left(\mathrm{Q}-\mathrm{q}_{\mathrm{H}}\right)\right]\end{array}$ \\
\hline & \multirow{2}{*}{ Negative } & High (p) & $\begin{array}{l}{\left[(\mathrm{s}+\mathrm{DR}-\mathrm{DC}-\mathrm{RC}) \mathrm{r} \cdot \mathrm{q}_{\mathbf{H}}+(\mathrm{s}-\mathrm{RC}-\mathrm{UC})(1-\mathrm{r}) \mathrm{q}_{\mathbf{H}},\right.} \\
\left.(\mathrm{ER}-\mathrm{s}) \mathrm{q}_{\mathbf{H}}-\mathrm{TC}\left(\mathrm{Q}-\mathrm{q}_{\mathbf{H}}\right)\right]\end{array}$ \\
\hline & & $\operatorname{Low}(1-p)$ & $\begin{array}{l}{\left[(s+D R-D C-R C) r \cdot q_{L}+(s-R C-U C)(1-r) q_{L}\right.} \\
\left.(E R-s) q_{L}-T C\left(Q-q_{L}\right)\right]\end{array}$ \\
\hline
\end{tabular}

When government subsidizes and enterprises recycle negatively, the High Quantity $\left(\mathrm{q}_{\mathrm{H}}\right)$ and Low Quantity $\left(\mathrm{q}_{\mathrm{L}}\right)$ happens in the possibilities of $p$ and $(1-p)$, respectively.

The expected revenue of enterprises is:

$$
\begin{aligned}
\mathrm{R}_{\mathrm{E} 22} & =\mathrm{p}\left[(\mathrm{s}+\mathrm{DR}-\mathrm{DC}-\mathrm{RC}) \mathrm{r} \cdot \mathrm{q}_{\mathrm{H}}+(\mathrm{s}-\mathrm{RC}-\mathrm{UC})(1-r) \mathrm{q}_{\mathrm{H}}\right]+(1-\mathrm{p})\left[(\mathrm{s}+\mathrm{DR}-\mathrm{DC}-\mathrm{RC}) \mathrm{r} \cdot \mathrm{q}_{\mathrm{L}}+(\mathrm{s}-\mathrm{RC}-\mathrm{UC})(1-\mathrm{r}) \mathrm{q}_{\mathrm{L}}\right] \\
& =\left[\mathrm{p} \cdot \mathrm{q}_{\mathrm{H}}+(1-\mathrm{p}) \mathrm{q}_{\mathrm{L}}\right][\mathrm{s}-\mathrm{RC}+(\mathrm{DR}-\mathrm{DC}) \mathrm{r}-\mathrm{UC}(1-\mathrm{r})]
\end{aligned}
$$

The expected revenue of government is:

$$
\begin{aligned}
\mathrm{R}_{\mathrm{G} 22} & =\mathrm{p}\left[(\mathrm{ER}-\mathrm{s}) \mathrm{q}_{\mathrm{H}}-\mathrm{TC}\left(\mathrm{Q}-\mathrm{q}_{\mathrm{H}}\right)\right]+(1-\mathrm{p})\left[(\mathrm{ER}-\mathrm{s}) \mathrm{q}_{\mathrm{L}}-\mathrm{TC}\left(\mathrm{Q}-\mathrm{q}_{\mathrm{L}}\right)\right] \\
& =\left[\mathrm{p} \cdot \mathrm{q}_{\mathrm{H}}+(1-\mathrm{p}) \mathrm{q}_{\mathrm{L}}\right][(\mathrm{ER}-\mathrm{s})+\mathrm{TC}]-\mathrm{TC} \cdot \mathrm{Q}
\end{aligned}
$$

To sum up, when the subsidy $s$ (from government to enterprises, per appliance) meets $E R+T C>s>\frac{H C \cdot q_{H}}{\left(q_{H}-q_{L}\right)(1-p)}+R C-(D R-D C) r+U C(1-r)$, the stage game can have the ideal result of (Subsidize, Recycle positively).

\section{Case Study of Promoting the Reverse Logistic}

We use the data of Shanghai to analyze the RL of TV (supposed), including its environmental benefit, cost and revenue of different recycled amount.

Analysis of Environmental Benefit. Nearly 300, 000 televisions are scrapped each year in Shanghai. We figure out the resource value of wasted TVs with the constitution and price information (Table 5).

Table 5 Resource Value of Wasted TVs

\begin{tabular}{crcc}
\hline \multirow{2}{*}{ Material } & $\begin{array}{c}\text { Weight } \\
\text { [Ton] }\end{array}$ & $\begin{array}{c}\text { Price } \\
\text { [Yuan per ton] }\end{array}$ & $\begin{array}{c}\text { Value } \\
\text { [Thousand yuan] }\end{array}$ \\
\hline Iron & 900 & 2,300 & 2,070 \\
Copper & 225 & 43,250 & $9,731.3$ \\
Aluminum & 75 & 13,400 & 1,005 \\
Plastic & 1,950 & 5,250 & $10,237.5$ \\
Glass & 3,975 & 500 & $1,987.5$ \\
Total & - & - & $25,031.3$ \\
\hline
\end{tabular}

The environmental loss of the 300, 000 televisions is reported to be $16,355.4$ million RMB yuan, therefore the environmental benefit of RL of wasted TVs is 41,386.7 million RMB yuan, 137.96 each.

Analysis of Economic Cost and Revenue. Nearly 300, 000 televisions are scrapped each year in Shanghai. We figure out the resource value of wasted TVs with the constitution and price information (Table 5).

We put forward the following assumptions: 
1. The number of waste household appliances continues to increase;

2. With the increase of recycled amount, the unit disposing cost continues to fall, and eventually converges to a constant. The relationship between the reprocessing price $\mathrm{Cr}$ and the recycled amount $\mathrm{q}$ is: $\mathrm{Cr}=\mathrm{k} / \mathrm{q}+\mathrm{a}$, where $\mathrm{k}=2 \cdot 106, \mathrm{a}=25$.

3. The discount rate is 0.9496 .

4. The opportunity cost is calculated by multiplying enterprise total investment with the social discount rate $(8 \%)$.

According to the literature, the average price to recycle a wasted TV in China is about $55 \mathrm{RMB}$ yuan, and the amount of WHA recycled through normal channels accounts for only $20 \%$ of all the WHAs. Based on these data, the amount of wasted TVs recycled through normal channels in Shanghai is only 60 thousand. And based on the analysis in Sector 5.1, the maximum revenue of a TV can be $\mathrm{Cr}$ $=25.031 / 30=83.43 \mathrm{RMB}$ yuan.

With the continuous expansion of the scale of the recycling, the subsidies government should pay are gradually reduced, namely the cost of enterprises is constantly decreasing. At the same time, however, enterprise themselves cannot solve the problem of losses, which must be subsidied by the government. By this stage of the case and in a market mechanism, the problem of RL of the WHA cannot be solved only by expansion. (See Fig. 1)

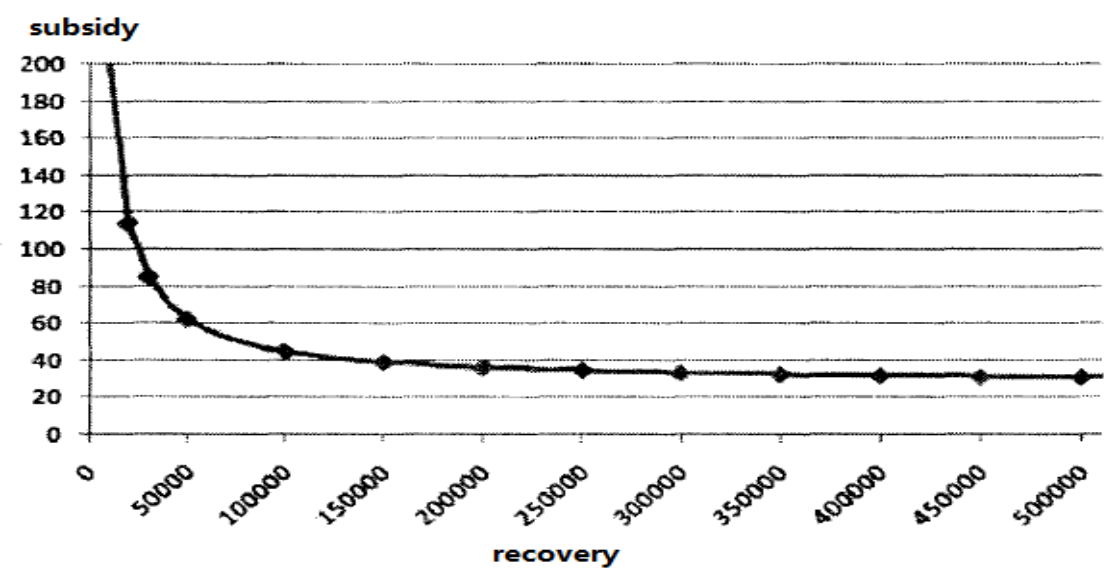

Figure 1 Subsidies and the recycled amount

Then we discuss the relation between the recycling price and the subsidy. We can draw from Fig. 2 that when the recycled amount is low (less than 60,000), enterprises can recycle without subsidy only when the recycling price is close to 0 ; and when the recycled amount reaches 150,000 and 240,000, the recycling price only need to reach 18 and 22 respectively to ensure that enterprises conduct the RL actively. 


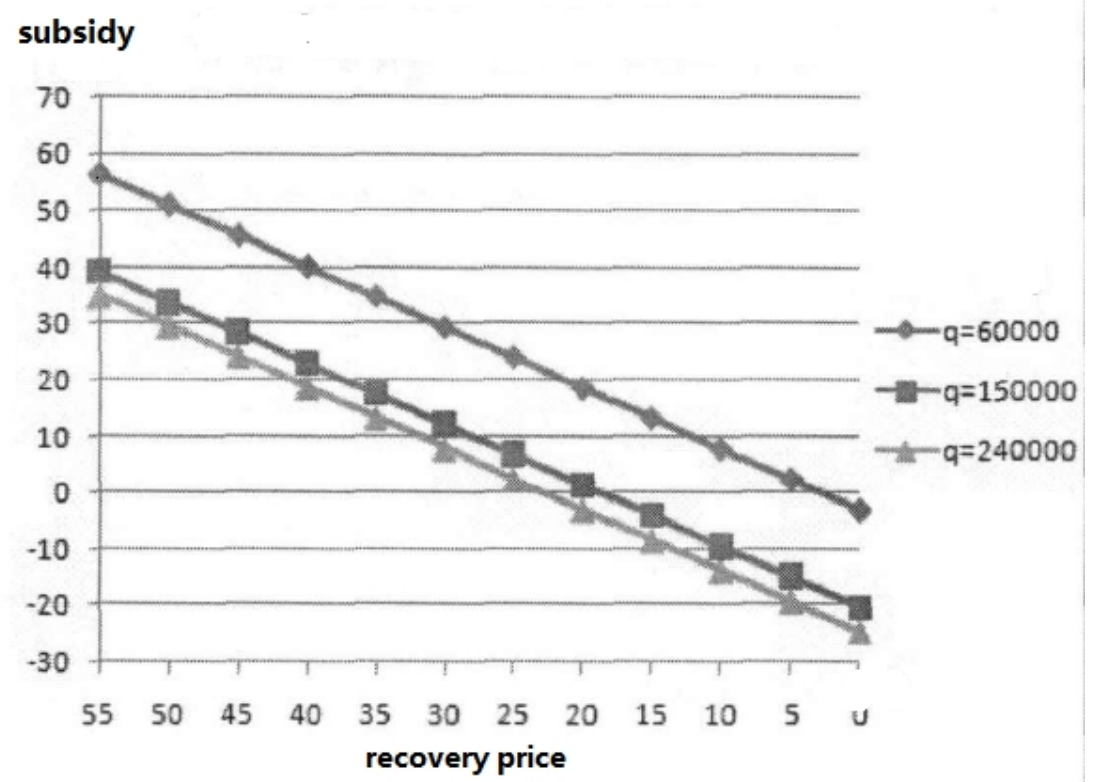

Figure 2 Subsidies and the recycling price

\section{Design of the Incentive Mechanism in the Reverse Logistics}

From the above analysis, we know that the RLS of WHA won't be established and operated. Only an effective incentive mechanism can stimulate enterprises to actively participate in it. As the guide and main enabler of RL at the present stage, government should adopt different promotion policies according to different periods of RL of WHA to promote the development of RL. We propose promotion strategies government should take in the RL of WHA as follows:

(1) Legislation and regulation. Ban small dismantling plant of hand-workshop style with low levels of technology and extensive treatment. Strengthen law enforcement, and punish enterprises not adopting the RL of WHA severely. Restrict on imports of electronic waste strictly and crack down on smuggling of waste electronic products behavior.

(2) Improve the access threshold for RL of WHA. Set up chartered qualification license system of recycling, perform strict market access and accreditation, and strongly support technology advanced and environmentally friendly enterprises. Set diversified way of recycling, intensify efforts to build RLS of WHA, and promote the normative and order development of the industry.

(3) Establish technical specifications and standards. Limit the use of toxic and hazardous materials in the production of household appliances, encourage the use of new environmentally friendly materials, and reduce the use of precious metals and rare metals, in order to reduce the damage to the environment and the waste of resources, and facilitate the recycling of WHA.

(4) Improve the financial subsidy mechanism. Government should adapt different subsidiary level according to the actual situation of enterprises. By establishing special fund, support RL enterprises, help enterprises carry out technological transformation and upgrade, and enhance resource recycling rate.

(5) Establish the extended responsibility system of producers and clear the main responsibility. Cooperate with suppliers and retailers apart from product manufacturers and importers to increase the flexibility and feasibility of implementation of the system. Ensure that the implementation of extended producer responsibility guarantees the economic interests of the participating enterprise as well as acquire social and environmental benefits.

(6) Enhance environment protection publicity, so that consumers will consciously pass WHA to formal processing factory and buy products produced by enterprises implementing RL of WHA and with good recycling performance. It can benefit both environmental enterprises and consumers, and more importantly, maintain the balance of the ecosystem. 


\section{Conclusion}

In conclusion, from the perspective of government, severe punishment legislation should be enacted to strengthen the supervision over enterprises and to reduce the possibility of enterprises' negative recycling. And reasonable subsidy rates should be determined according to the real situation of the market and enterprises to encourage enterprises to establish and operate the RLS positively.

From the perspective of enterprises, they can reduce the unit cost of reprocessing WHA through the increase of recycling scale and the improvement of technology.

For the public, the significance of environmental protection should be promoted in order to enhance the environmental awareness, and solve the problem of WHA through the cooperation and effort of all the parts.

\section{References}

[1] M. Klausner, C. T. Hendrickson, Reverse logistics strategy for product tack-back, Interfaces. 30 (2000) 156-165.

[2] H. Li, H. Shi, Reverse logistics system planning for recycling electrical appliances-and computer in Taiwan, Resources, Conservation and Recycling. 32 (2001) 55-72.

[3] L. H. Tung, B. S. Jiuh, H. H. Kuan, A reverse logistics cost minimization model for the treatment of hazardous waste, Transportation Research. 38 (2002) 457-473.

[4] D. Hammond, P. Beullens, Closed-loop supply chain network equilibrium under legislation, European Journal of Operational Research. 183 (2007) 895-908.

[5] G. Dai, Urban construction waste household appliances recycling system, Urban Problems. 3 (2008) 78-81.

[6] P. Zhu, Recycling and disposal of waste household appliances and electronic products in our country present situation and the countermeasures, Renewable Resources and Recycling Economy. 1 (2010) 32-35.

[7] C. Wang, The dynamic analysis model of reverse logistics, Navigation of China. 4 (2003) 78-80.

[8] X. Jia, J. Rang, The game analysis of reverse logistics, Journal of Hangzhou University of Commerce. 2 (2005) 9-13.

[9] J. Li, W. Liu, G. Chen, Game analysis about reverse logistics between government and enterprise, Journal of Northwest A\&F University (Social Science Edition). 5 (2007) 54-57.

[10]W. He, Z. Ma, Dynamic multidimensional game analysis of returned logistics implemented by household appliances manufacturers, Journal of Southwest Jiaotong University. 4 (2008) 519-523.

[11]J. Li, Y. Liu, Repeated game under the perspective of enterprise environmental behaviour, Shandong Social Sciences. 2 (2008) 64-67.

[12]X. Liu, S. Chen, Research on incentive mechanism of government in reverse logistics, Journal of Harbin University of Commerce(Social Science Edition). 1 (2009) 46-48. 